\title{
Integrated biosystems for resource conservation in rural industries: an Australian experience
}

\author{
Judith McNeill*, Rex Glencross-Grant, Annemieke van der Meulen \\ Institute for Rural Futures and Department of Environmental Engineering, University of New England, Armidale, \\ New South Wales 2351, Australia
}

\begin{abstract}
For many years now, industrial production structures have started with raw materials and other inputs and finished with manufactured goods and waste products. These linear pathways are contributing to natural resource shortages, increased emissions into the atmosphere, pressure on water supplies, and problems with disposal of steadily accumulating solid wastes. Within the new science of industrial ecology, 'integrated biosystems', wherein the wastes and by-products of one firm are used as inputs for another firm, is a means of creating a 'waste loop'. In theory, this can achieve more 'service' from a given amount of natural resource use at the same time as lowering some input costs and environmental impacts. In Australia, a research team, which includes the authors, is attempting to design and implement such a system amongst a group of co-located firms in a rural town. This paper reports on our experience to date, with a view to alerting policy-makers to the potential benefits of such projects and also to some unexpected institutional constraints we have encountered. The constraints will need to be addressed before initiatives such as this can become commonplace.
\end{abstract}

KEY WORDS: Integrated biosystems · Industrial ecology $\cdot$ Industrial symbiosis · Ecological economics Industry clustering $\cdot$ Sustainable development $\cdot$ Regional development

Resale or republication not permitted without written consent of the publisher

We have used the land, the air and the water as our garbage dump and the dump is full

D. Suzuki, 1993

\section{INTRODUCTION}

This paper reports on our experiences gained in beginning a resource conservation project in an industrial estate in a rural city in Australia. Since the industrial revolution, rapidly increasing population and fast economic growth have intensified pressures on the earth's systems and resources. The pace and scale of change and its impacts on, below and above the earth's surface are said to constitute something of an evolutionary gamble with the planet (McNeill 2000). The effects of soil degradation, water and air pollution, increased presence of greenhouse gases, ozone depletion, deep ocean dumping, wetland draining, deforestation, microbial resistance, bio-invasions, fisheries collapse and erosion of biodiversity are all inherently uncertain. What can be said with some certainty is that the present industrial path is not sustainable and that the natural resource inputs (the 'natural capital') into the system will become increasingly scarce, and disposal of wastes more costly and potentially environmentally risky.

Efforts to 'dematerialise' or 'decouple' industrial production and natural resource inputs are being made (OECD 2002, 2004). However whilst progress is impressive when decoupling is measured on a per capita or per unit of economic output basis, this success is much less apparent when resource use and waste flows are measured in absolute terms (WRI 2001). In many instances, the rate of expansion as the economy 
grows simply outweighs the progress being made. Municipal waste in particular, is given 'red light' status in the OECD's projections of environmental pressures to 2020. This means that it is potentially a 'major problem area and needs to be addressed urgently' (OECD 2001, p. 11)

Against this background, it is clear that efforts to increase the efficiency with which scarce natural capital is being used and to divert materials from landfill have a strong claim to research and policy agendas. In this paper a relatively novel approach to waste reduction and natural resource efficiency is described where, by using biological processes or other re-use options, the wastes and by-products of one industry are used as inputs for another to, ultimately, close a waste loop. These integrated biosystems of waste and energy re-use require research into the nature of the processes by which waste products or by-products of a firm can be transformed into useful resources for other firms (see for example, Rural Industries Research \& Development Corporation 2002). Specific options to research will depend on the nature and location of the firms in an area and will therefore be site specific. Whilst it would be possible to design systems in urban areas, the industries that tend to predominate in rural landscapes, such as agriculture, aquaculture, horticulture, stock-feed manufacture, abattoirs and other food processing, are particularly suited to integrated biosystem design, and are therefore a good place to pioneer how re-use links might be made between firms.

In reporting on our experience with the project in this paper, we have 3 main objectives: (1) to outline our ethical stance as to why we are undertaking the project; (2) to explain how we are going about it, including an assessment of its opportunities as well as some difficulties being experienced; and (3) to alert policy makers to the opportunities such projects afford and also to some unexpected institutional constraints we have encountered and which will need to be addressed if initiatives like this are to become commonplace.

\section{THE ETHICAL STANCE OF THE AUTHORS}

The unsustainable pattern of industrial growth derives from the current pressures on the earth's sources and sinks and the uncertain and complex ecological interdependencies inherent in these pressures. These are biophysical limits to economic growth. In addition to the biophysical constraints, there are ethical considerations which motivate research into ways to reduce wastes and increase the efficiency of use of natural capital. Following Daly (1996, p. 33-37), it may be argued that it is undesirable on intergenerational equity grounds to finance economic growth of the pre- sent generation by a drawdown of natural capital, the subsequent scarcity of which will impose a cost on future generations. To put a finer point on it, Daly (1996, p. 36) says that the principle for balancing present against future might be that:

The basic needs of the present should always take precedence over the basic needs of the future, but the basic needs of the future should take precedence over the extravagant luxury of the present.

Restraint on the drawdown of natural capital to avoid future costs is a principle which subsumes, and would prescribe effective actions now to mitigate, global warming, but this extremely complex issue has many other ethical aspects that compel attention (see, for example, Brown 2001). Most notably, it is apparent that global warming will affect the health and livelihoods of people in countries least able to cope with it. Sustainability is therefore a matter not only of intergenerational equity, but also intra generational and international equity.

A second ethical consideration concerns the environmental impacts on biodiversity. Other species have an instrumental value to humans, which should place limits on the extent to which we are prepared to take over their habitat, but they may also be regarded as having an intrinsic value and a right to their 'place in the sun' (Daly 1996, p. 36). It is admittedly a major problem in philosophy and ecology to state what this limit should be on either grounds. However, with this, as with other actions directed towards achieving a more environmentally sustainable industrial structure, it is highly likely that serious and irreversible damage will occur before all the uncertainties can be removed.

\section{THE CASE STUDY: AN INTEGRATED BIOSYSTEM IN RURAL AUSTRALIA}

\section{Background}

The Glen Artney Estate, an agro-industrial complex located in the rural Australian city of Tamworth, has been selected as a study site for integrated biosystem research. This project is a research initiative of the University of New England (UNE), located in a neighbouring region of New South Wales (NSW). The project requires cross-disciplinary understanding of industry processes, and involves researchers from numerous backgrounds, including economists, environmental engineers, and natural resource scientists/managers and planners. These researchers are collaborating with the processing industries on the site and with the local government (Tamworth City Council). The Glen Artney Estate comprises 16 business 
operations, comprising meat processors (including 2 abattoirs), a commercial laundry, a liquefied petroleum gas (LPG) supplier, a scrap metal dealer, poultry processing, road and paving product suppliers, fuelling systems and equipment suppliers, a wholesale food supplier, a hydroponics tomato operation, a construction firm and the Tamworth Regional Saleyards (IRF 2004).

Specific objectives of the project are to identify the agro-industrial by-products available to be used as inputs in other neighbouring industries, to outline the present state of knowledge of processes for recycling agro-industrial by-products, and to evaluate alternatives for selected by-product re-use. Final year undergraduate students have been encouraged to select honours projects which will contribute to knowledge in evaluating re-use options. To date, these have resulted in a number of detailed areas of study that have seen the application of theory to practical solutions in a multi-disciplinary environment.

\section{Project initiation}

The project began in a rather informal way with the 2 principal researchers (J. McNeill and R. Glencross Grant) holding preliminary discussions with 2 managers in the Estate. One manager was from a meat processing facility and the other from a hydroponic cropping operation. What was particularly interesting was the number of ideas, which emerged immediately in these first discussions. It was determined that the key resources of interest to these operators were water (in both cases) and heat/carbon dioxide in the case of the vegetable growing operation. The manager of the latter operation knew, for instance, that if he could elevate his indoor air temperature by only a few degrees he could produce a crop all year round.
Similarly, he had anecdotal evidence that enhancing the carbon dioxide level in the greenhouse could increase his production potential. The meat-processing manager also was faced with a disposal problem of vegetative material from slaughtered animals. Armed with this on-site evidence, the researchers initially set up 2 undergraduate student projects. One project involving the abattoir was aimed at water harvesting and storage potential. The other project (explained in more detail below) was based on assessing the potential for capturing and utilising carbon dioxide as an exhaust gas from heating water with propane. Both projects were conducted between March and October 2003. A third project, begun in March 2004, is examining feasible solutions for dealing with vegetative by-products and a fourth 2004 project involves research into the possibilities for cogeneration on the site. The focus of all of these projects has been their potential to contribute to 'value adding' to waste and the closing of waste loops. Each project involves quite complex, multidisciplinary research. To illustrate, one of the recently completed projects, the carbon dioxide re-use project, is described in more detail below.

\section{An investigation into whether 'waste' carbon dioxide from an abattoir might be captured and re-used to boost plant growth in a hydroponics operation}

The project involved working closely with 2 specific business operations in the Glen Artney Industrial Estate in Tamworth, Northern NSW. The specific operations studied in this instance are the sheep meat abattoir and the hydroponic tomato operation. Both businesses were independently established on the Estate. Inputs and outputs for both operations were listed and are shown schematically in Fig. 1, together with oppor-

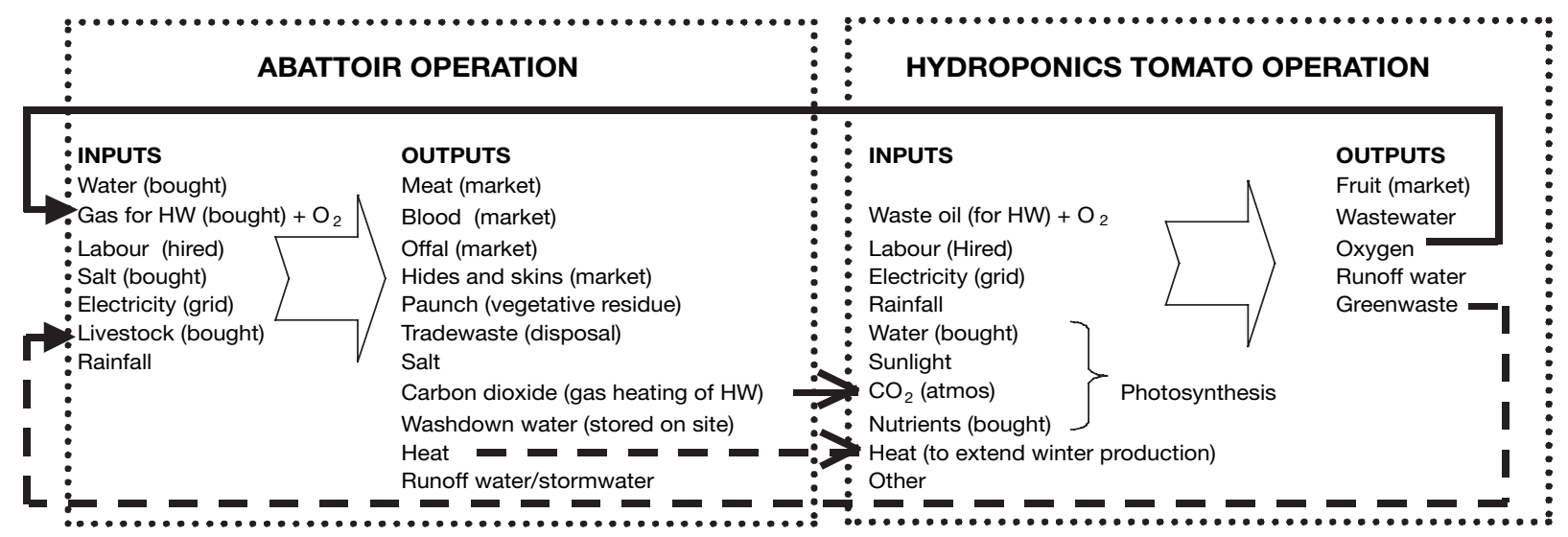

Fig. 1. Input/output model for abattoir and hydroponics operation at study site. Dotted lines indicate operational boundaries; solid arrow lines indicate what can be achieved immediately and dotted arrows indicate what is potentially possible in the future for the study site. HW = hot water 
tunities for interconnections. As well, future opportunities for further connections have been indicated in Fig. 1.

These inputs and outputs can be represented in a flow diagram as in Fig. 2.

The principal objectives of the carbon dioxide re-use study (van der Meulen 2003, p. 3) were to:

- Determine if the boiler emissions were a safe and adequate source of $\mathrm{CO}_{2}$

- Evaluate the costs of using boiler emissions as an alternative source of $\mathrm{CO}_{2}$

- Identify and cost other alternatives available for the hydroponics operation including no enrichment ('do nothing' approach), and

- Determine the most profitable alternative.

The van der Meulen (2003) study firstly assessed the quality of the flue gases from the combustion of propane at the abattoir and then determined whether there would be sufficient quantity to sustain the hydroponics operation. It was demonstrated that even though the abattoir was a Monday-Friday operation, there was sufficient $\mathrm{CO}_{2}$ to enable daily use of $\mathrm{CO}_{2}$ for sustained hydroponics operation, with sufficient excess to provide a 'safety margin'. Principal issues were (1) that optimum concentration levels of $\mathrm{CO}_{2}$ in the glasshouses should foster optimum plant growth and fruit production, yet provide a safe working environment for employees, (2) that there were not other harmful exhaust gases that may cause problems to employees (dependent on fuel used and efficiency of combustion), and (3) that too much $\mathrm{CO}_{2}$ did not escape from the greenhouses to the outside environment, thereby defeating or substantially reducing the dual objectives of reduced impact of greenhouse gases and enhanced crop production.
It was demonstrated that 10 to $40 \%$ increase in productivity could be achieved with plants growing in a $\mathrm{CO}_{2}$ enriched environment. The actual increase will be dependent on the concentration of $\mathrm{CO}_{2}$, the amount of available sunlight, ambient temperatures, nutrient level and water. For purposes of the study and economic analysis, $15 \%$ was assumed as a conservative estimate of the expected increase in productivity. Thus, in terms of preliminary economic analysis (based on a technique similar to cost benefit analysis called 'partial budgeting') it was demonstrated that the option of using boiler emissions, compared with a 'do nothing' approach, or that of using enrichment generators, resulted in a potentially more profitable outcome (van der Meulen 2003). Also, there were advantages in reducing the impact of greenhouse gases from the boiler emissions. However, this was difficult to quantify because of lack of carbon-trading values at this stage. As an approximation, a range of AUD\$10-\$50/ tonne was advisedly taken (AGO 2000) and the effect determined for the various rates as part of the sensitivity analysis. For instance, if $\mathrm{CO}_{2}$ emissions are priced within the AUD\$10-\$50 ranges, savings of the order of AUD\$1200-\$6000 could be achieved for the abattoir if a carbon credit system were in place and the gas could be captured safely and directed through the hydroponics operation. However, a carbon credit system is not in place, so this is purely speculative at this stage.

In the overall economic analysis, the one aspect that was most sensitive to profitability was the product price. It is clear that marketing aspects such as presentation and product differentiation are vitally important to maintain the price differential for hydroponic tomatoes compared with other mass-produced product.

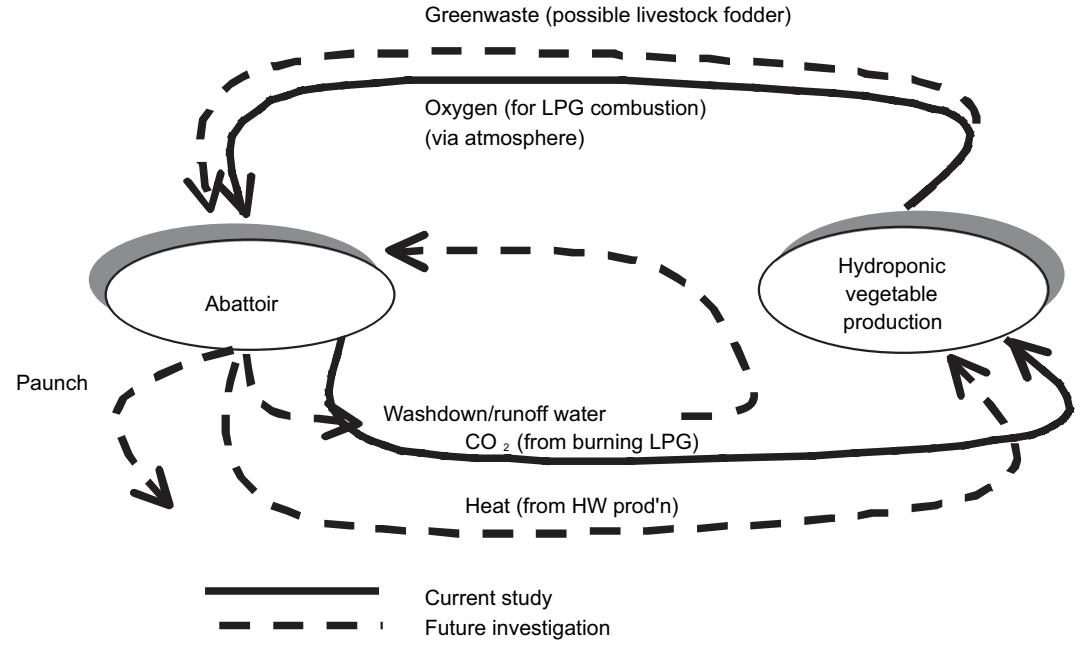

Fig. 2. Proposed flow model of study site showing interdependency of the 2 industries and opportunities for flows of outputs and inputs across operational boundaries. HW = hot water, LPG = liquified petroleum gas

\section{Longer-term plan for an environmental cluster of industries at the site}

The project area is continuously developing and evolving, and the Estate still contains vacant land for further industries. Accordingly, the project coordinators are engaged in consultation with business leaders and with other agro-industries scattered throughout the Tamworth district. At this time, close co-operation is somewhat limited by geographical dispersion. However, the local council has a long-term goal of clustering industry at the Glen Artney Estate. The consultations with business leaders and with the local council have helped to provide information on waste products and practices, and 
facilitate the addition of new ideas and initiatives to the project. One notable idea to emerge so far from these meetings has been for government and industry to collaborate in producing an organic input/output regional mapping project. This 'map' should provide valuable information to aid clustering of compatible industries with synergistic production processes in the region.

\section{THE OPPORTUNITIES PRESENTED BY THE PROJECT}

\section{Direct environmental benefits}

The project's foremost advantage is the potential it offers to reduce the environmental impact of firms' current production methods. For example, greater efficiencies would be achieved in water use (an important aspect given that the town is currently rationing scarce water supplies), and substantial reductions would be made in the amount of both liquid and solid waste going to landfill. Also, a net reduction in carbon dioxide release into the atmosphere is possible if the carbon dioxide produced as a byproduct of LPG combustion could be re-used in hydroponics, thereby avoiding the necessity for the hydroponics firm to buy carbon dioxide.

\section{The prospect of lower input costs}

The firms keenest to participate in the research project had 2 possible benefits in mind. The first was the prospect of having to pay less for certain inputs and the second was to be able to present a 'cleaner and greener image', in other words, one of environmentally astute corporate citizenship. Lower input prices are clearly the most direct and obvious benefit to firms. The prospect for lowering costs currently being paid for water, for example, were very good, because the firms in the Estate used large amounts of water (around one quarter of the whole City's consumption) and water must be paid for both on the way in, and also on the way out (where it goes into the town sewerage system for treatment). Although regulations prevent the abattoirs in particular, from taking advantage of some of the more obvious ways of re-using water, the biosystem project extends the re-use possibilities. Additionally, because of longterm pressures on water availability in Australia, the price of water to businesses is very likely to rise substantially over the next decade. This clearly increases the wisdom of searching for ways to save and/or reuse water.

\section{A cleaner and greener image}

The cleaner and greener image, which several of the firms were keen to pursue, is a less tangible direct benefit to firms than lowering input costs, but there is a prospect of securing more custom from consumers who watch such credentials carefully. To be frank however, it is possible, reading between the lines, that the strongest motive operating in this regard for at least one firm was that of getting the local council 'off their back' (or at least more 'on side'), for instances when noise, storm-water drainage, expansion plans or similar infrastructure issues required sensitive negotiations with the local council.

\section{Regional development: attraction of new businesses to the area to form a cluster}

The project hopes to facilitate ongoing cooperation between the university, local government, NSW State Government, business groups and industry representatives from both existing firms and newcomers to the Estate. The local council has a long-term regional economic development plan to cluster industries in Glen Artney, and it is therefore likely that the potential for material linkages will be increased due to a greater diversity of inputs, outputs and production processes. There is also the potential to identify specific industries that may further assist in closing particular loops, and these can be encouraged to join the Estate for increased benefit. This in turn, may encourage new firms to choose the Estate as a business location over other areas without such clusters. The clustering together of a number of firms is now well recognised in the literature as a way to improve economic and environmental performance (Porter 1990). Cluster arrangements can reduce costs. This can be done through achieving symbiosis in wastewater and energy management such as are being envisaged in this project, but firms can also extend the newly acquired habit of co-operating into other business functions such as joint procurement, marketing and product promotion projects. Firms in the project have mentioned the increased business, as well as social, connectedness as a distinct benefit of the whole initiative. Clustering theory and practice also suggest that interaction and knowledge exchange between firms and universities can increase innovation in other areas within the firms (Roelandt \& den Hertog 1999).

\section{Replication of the project research to other areas where there are similar industries}

Although it is a local initiative, it is hoped that the benefits of the Glen Artney research project will not be 
exclusive to Tamworth. Rather, it is hoped the project may yield results that can be transplanted to similar complexes where food processing predominates around the world, thus extending the environmental benefits.

\section{Benefits of the research to the university}

Conducting research into real world issues facing local firms brings benefits to the university undertaking it. Foremost perhaps, is that the profile of the university is raised by its engagement with the region. The tendency to dismiss universities as a source of 'ivory tower' impractical advice can be displaced by a greater understanding between the university and project participants, and a constructive search for mutually beneficial opportunities. We have noticed that many researchers are keen to do something useful, but in the absence of close links with the nonacademic world, do not always know how to do this. On the other hand, there are many businesses, particularly small businesses that either do not think to, or do not know how to, approach a university for help. As well, in recent years in Australia there have been pressures for universities to obtain a greater proportion of their funding from local community sources. Clearly, closer relationships between the university and the region will be essential in this regard.

Students also benefit by working in multidisciplinary teams attempting to address real world problems. In recent decades student training has tended to be in a single discipline, but this can bring problems, as Daly \& Farley (2004, p. 22) describe:

Rather than training students to examine a problem and apply whatever tools are necessary to address it, they are trained in a set of discipline-specific tools that they are then expected to apply to all problems. The difficulty is that most pressing problems we face today arise from the interaction between two highly complex systems - the human system and the ecological system that sustains it. Such problems are far too complex to be addressed from the perspective of a single discipline, and efforts to do so must either ignore those aspects of the problem outside the discipline, or apply inappropriate tools to address them.

\section{SOME DIFFICULTIES WITH IMPLEMENTATION OF THE PROJECT}

It is well known in the literature on government policy that actually implementing a sound idea or policy is often much more difficult than coming up with the idea in the first place (Pressman \& Wildavsky 1984). Trying to effect changes, for purposes that sound like extraordinary commonsense in the face of strong evidence that a current path is dangerous, inequitable and unsustainable, is no exception. In fact, it could be said that one of the weaknesses in the literature on industrial ecology, and integrated biosystems in particular, is that insufficient attention is paid to difficulties of implementation and what might be done about them. Some of these difficulties and some measures which might assist are described below.

\section{Financial incentives to participate are not strong because existing inputs are subsidised}

The first, and perhaps most intractable difficulty affecting the success of projects like integrated biosystem design is that subsidised prices for water, energy (derived from fossil fuels), and waste disposal (including untaxed air emissions as well as solid wastes), reduce very significantly the direct financial incentives for firms to give up their time in order to participate. It has been mentioned above that the prospect of lowering input costs was an inducement for some firms to participate. However, when existing water, electricity, waste charges and the like, are subsidised, firms have much less incentive to go to the trouble to change the way they do things than they would if the inputs were correctly costed. In Australia, as elsewhere, this will change as the inevitable price rises occur over future years, but at the moment the extent to which it is currently not worth changing practices because of the relatively small effect on a firm's profits, seems to be under-appreciated by those of us somewhat naively exhorting a more sustainable path for the sake of humanity. In economic terms, a major component of the costs of the present industrial production procedures is external to the firms undertaking the production - hence these costs are 'externalities'. If price signals more fully reflected these externalities, then these prices would be taken into account in production and consumption decisions economy-wide. At the moment, the signals are not strong enough to encourage change.

If these existing subsidies produce 'lock in' effects to the prevailing way of doing things, thus inhibiting the development of more environmentally benign ways of producing goods and services, then one way around this, given that raising costs to business is politically unpalatable, is to subsidise environmentally friendly technologies. This would pose a counter-balance to the existing price distortions, allow 'learning curve' time to develop new technologies and bring forward the time when safer alternatives become competitive. Also when government subsidy programs for alternative technology development become available, they need to be well advertised, set in clear language and acces- 
sible by firms or researchers. We have found very few firms aware of what is available, and even when they are aware of some assistance, reluctant to take the time to go through the necessary hoops. An alternative option for governments is to raise the prices of the inputs of existing technologies to more closely reflect their true cost and encourage firms to find alternatives. Offering at the same time offsetting taxation or rate relief could assuage the political difficulty of raising charges. Overall a firm would not be worse off. However, the firm would find it profitable now to search for environmentally benign technologies.

\section{Reluctance of some firms to collaborate}

A second problem in implementing the Tamworth project is that some of the businesses in rural towns tend to be wary about collaboration with each another. Older businesses in rural areas are used to viewing their competitors as rivals, rather than friends with whom to collaborate.

It appears that it is also quite common for the typical problems of co-location (i.e. stormwater run-off, noise, dust, etc.) to have caused some friction between businesses in the past. Building the trust necessary to collaborate effectively on resource conservation may therefore have to overcome some difficult histories and may take some time. Importantly, it may be wise to learn the history of business relations between firms as much as possible prior to commencing discussion of cooperation.

\section{Temporary disturbances to security of supply of an input}

One possible problem of taking advantage of a 'symbiosis' between firms could well be that it then sets up an inherent reliance of one industry on another. For instance, factors beyond the control of either business could impose a temporal variation on the supply of by-products, e.g. drought conditions could see a reduction in livestock available for slaughter and therefore a reduction in abattoir operational time, which could then impact upon enhanced production of the hydroponics operation. It is clear that alternative back-up sources of supply would have to be arranged.

\section{Difficulties in getting local councils 'on side'}

A third conundrum can arise with relatively ambitious projects such as integrated biosystem design if local government is unfamiliar with the notion. Local councils tend, not unreasonably, to operate in the paradigm of large-scale provision of essential services in order to achieve economies of scale. As such, they may treat with suspicion projects that will reduce the demand for the services they provide as their core business (i.e. water supply, wastewater treatment and garbage collection and disposal), particularly if resources are being diverted and re-used on-site at the industrial estate within a 'closed' system. Local government has tended, philosophically, not to work within a closed system environment, quite the contrary; its systems have tended more to openness, although this is changing with recent waste legislation in NSW.

\section{Developing the science will take time}

A final challenge in implementing integrated biosystem initiatives is that the science itself, designing and improving integrated systems, can be quite complex, and will certainly take some years exploring and refining. This is not always appreciated and can cause problems. For example, if an agency is allocating grants with an objective of reducing wastes going to landfill, then it is highly likely that the shorter-term 'fixes' that can show good results to a Minister after a year will be chosen. However, short-term measures do not adequately come to grips with the fundamentals of the problem.

\section{Difficulties undertaking multi-disciplinary research}

Researching real world problems provides excellent opportunities, but can cause difficulties for students at the moment because, as mentioned above, problems tend not to be solved within the single disciplinary boundaries to which most students are confined at universities. For example, in the carbon dioxide re-use project, a sound knowledge of parts of economics, chemistry, engineering and horticulture was required. It is highly desirable to train students in wider fields, but student supervision and training will be far more effective when university structures are better organised to facilitate cross-disciplinary studies. Most importantly, we believe that language barriers, such as jargon that often appears to be developed in order to protect a discipline's 'turf,' need to be lowered in order to develop clearer communication of ideas. In our experience it has been particularly rewarding to gradually gain insights from other disciplines into a problem, and it can extend and influence one's own perspective considerably. 
Table 1. Summary of opportunities and difficulties with designing integrated biosystems for groups of firms

\begin{tabular}{l} 
Opportunities \\
\hline Direct environmental benefits \\
E.g. Greater efficiencies in water use, substantial reductions in the amount \\
of liquid and solid waste going to landfill, possible net reduction in carbon \\
dioxide release. \\
The prospect of lower input costs \\
The most direct and obvious benefit to firms. Prospects for lowering costs \\
currently being paid for water are very good. Firms in the Estate use large \\
amounts of water and water is paid for both on the way in, and also on the \\
way out where it goes for treatment. Water is scarce in this part of NSW \\
and the town is currently rationing water. Firms' waste disposal costs will \\
also fall.
\end{tabular}

\section{A cleaner and greener image}

Possibility of attracting custom from buyers who value such efforts Improved relations with local council and local environment authority.

Regional development: attraction of new businesses to the area to form a cluster

Improved social and business networks; collaboration potential in other areas, e.g. joint procurement, marketing and product promotion projects; potential for greater innovation.

Replication of the project research to other areas where there are similar industries

Possibility of replicating some of the re-use possibilities for use by industry in similar complexes where food processing predominates.

\section{Benefits of the research to the University}

Students (and lecturers) receive training in real world multi-disciplinary problems. Barriers between single discipline departments start to fall. University engages usefully with businesses in its region.

\section{Difficulties}

Financial incentives to participate are not strong because prices of existing inputs are subsidised. They do not reflect costs that are external to the firm, such as the true scarcity of water or impact on the environment Most difficult problem of the whole project. Prices of current inputs are lower than they should be if they were more correctly priced; therefore, incentives to search for more benign alternatives are nowhere near as strong as they should be.

Reluctance of some firms to collaborate

For many firms in rural areas the idea of co-operating with neighbours is quite new. Firms are more inclined to see other firms as rivals.

\section{Temporary disturbances to security of supply of an input}

Factors beyond the control of either business, e.g. drought, could temporally disrupt supply of by-products on which another firm has come to depend.

Difficulties in getting local councils 'on side'

Reduced use of water by the Estate and less trade waste treated in the public system could conceivably reduce capital and operational return for the local government utilities charged with these responsibilities.

\section{Developing the science will take time}

E.g. It is not often appreciated by research granting agencies that with this type of inquiry 'performance indicators' cannot show significant improvement after a grant of $1 \mathrm{yr}$.

\section{Difficulties undertaking multi-disciplinary research}

Despite the inherent benefits of studying real world problems, it can be difficult for students and lecturers trained in one discipline to understand techniques and language of another. A better understanding of important real world problems would derive from institutional change at universities that returned at least some areas to multi-disciplinary departments or centres.
In summary, whilst there are significant long-term benefits to be gained from research such as biosystem design for groups of firms, there are also significant challenges to be faced. Formidable, but absolutely necessary changes to institutional structures must begin now. Opportunities and the difficulties are summarised in Table 1.

\section{CONCLUSIONS}

This paper has reported on our experiences gained in beginning a resource conservation project to design an integrated biosystem to create waste loops in an industrial estate in a rural city in Australia. The theory behind such systems rests firmly in ecologically sustainable development, to which we believe strong ethical considerations also attach. In addition to the environmental benefits, the development of small clusters of firms, which is encouraged by the design of such systems, offers an excellent prospect for towns to further their regional development aims. As well, the project affords invaluable student training in the complex real world science of sustainability. Realistically though, the implementation of the project has posed challenges to an extent we had not anticipated. These include encouraging firms to cooperate with one another, enlisting support from local government whose finances are dependent on continuing to operate in the paradigm of large scale provision of utility services, and getting universities to change single disciplinary structures that have existed for many years. However, the single most effective measure to encourage successful integrated biosystem design and similar projects would be to improve the financial incentives for firms to participate. This could be done by providing offsets (such as credits for co-generation) to the environmentally harmful subsidies that currently 'lock in' the existing ways of doing things, or by removing these subsidies altogether. 
Acknowledgemments. The authors would like to thank Resource NSW for finnancial assiatance for this project.

\section{LITERATURE CITED}

AGO (Australian Greenhouse Office) (2000) Greenhouse gas emissions trading: allocation of permits. Australian Greenhouse Office, Canberra

Brown DA (2001) The ethical dimensions of global environmental issues. Daedalus Fall 4:59-76

Daly H (1996) Beyond growth. Beacon Press, Boston, MA

Daly H, Farley J (2004) Ecological economics: principles and applications. Island Press, Washington, DC

IRF (Institute for Rural Futures) (2004) Designing a 'Best Practice' model of integrated biosystems of waste re-use in a typical rural town. Final Report for NSW Dept of Environment and Conservation RD1/S2/03/20, University of New England, Armidale

McNeill JR (2000) Something new under the sun: an environmental history of the twentieth-century world. Penguin, London

OECD (Organization for Economic Cooperation and Development) (2001) Environmental outlook. OECD, Paris

OECD (2002) Indicators to measure decoupling of environmental pressure from economic growth. OECD, Paris

Editorial responsibility: Brian Marcotte (Managing Editor), Portland, Maine, USA
OECD (2004) OECD Environmental strategy, 2004 review of progress. OECD, Paris

Porter M (1990) The competitive advantage of nations. The Free Press, New York

Pressman J, Wildavsky A (1984) Implementation: how great expectations in Washington are dashed in Oakland: or, why it's amazing that federal programs work at all, this being a saga of the Economic Development Administration as told by two sympathetic observers who seek to build morals on a foundation of ruined hopes. University of California Press, Berkeley, CA

Roelandt T, den Hertog P (1999) Cluster analysis and clusterbased policy making: the state of the art. In: Roelandt $\mathrm{T}_{\text {, }}$ den Hertog $\mathrm{P}$ (eds) Boosting innovation: the cluster approach. OECD Proceedings, OECD, Paris

Rural Industries Research and Development Corporation (2002) Integrated biosystems for sustainable development. RIRDC publication No 01/174, Canberra

van der Meulen AW (2003) An investigation into the utilisation of boiler emissions as a source of carbon dioxide for yield enhancement in tomato greenhouses. BSc thesis, University of New England, Armidale

Suzuki D (1993) Time to change. Allen and Unwin, Sydney

WRI (World Resources Institute) (2001) The weight of nations: material outflows from industrial economies. WRI, Washington DC, available at: http://materials.wri.org/ pubs_findings.cfm?PubID=3023

Submitted: August 12, 2004; Accepted: July 4, 2005

Proofs received from author(s): $X X X X, 2005$

Published on the web: XXXX, 2005 